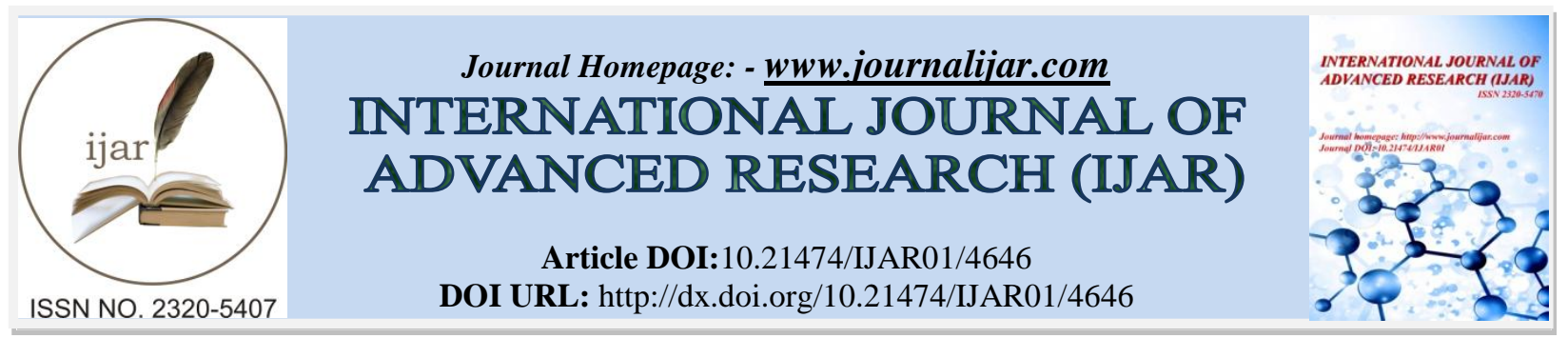

RESEARCH ARTICLE

\title{
EFFECT OF BORIC ACID ON ALVEOLAR BONE LOSS AND ITS ASSOCIATION WITH SERUM CALCIUM, ALKALINE PHOSPHATASE IN RATS: A HISTOMORPHOMETRIC\& BIOCHEMICAL STUDY.
}

\author{
Daya $S^{1^{*}}$ andDhoom S. Mehta ${ }^{2}$ \\ 1. Senior Lecturer, Department of Periodontics, Bapuji Dental College \& Hospital, DavangereKarnataka (India). \\ 2. Professor \& Head, Department of Periodontics, Bapuji Dental College \& Hospital, DavangereKarnataka \\ (India).
}

\section{Manuscript Info}

\section{Manuscript History}

Received: 26 April 2017

Final Accepted: 30 May 2017

Published: June 2017

Key words:-

Preconception Health care, Knowledge,

Risk behavior, chronic conditions.

\section{Abstract}

Objectives: The purpose of the present study was to evaluate the morphometric and histopathologic effects of systemic boric acid in a rat periodontitis model. It was also an intent of the present study to correlate it with the biochemical markers of bone metabolism i.e.serum calcium and alkaline phosphatase.

Methods: Thirty Wistar rats were divided into three groups of ten animals each: non-ligated (NL), ligature only (LO), and ligature and treated with boric acid (BA) (3mg/kg per day for 11 days). A 4/0 silk suture was placed in a subgingival position around the maxillary second molars; after 11 days the rats were sacrificed, and changes in alveolar bone levels were measured clinically and tissues were histopathologically examined to assess the differences amongst the study groups.Alveolar bone loss was measured under stereomicroscope and tissues were histopathologically examined to assess, osteoclast numbers and osteoblastic activity.

Results : There was statistically highly significant amount of alveolar bone loss in the ligature group (Group II) when compared to control and the boric acid group (Group III) $(\mathrm{p}<0.001)$. However in boric acid group (Group III), the bone loss was decreased significantly when compared to group II $(\mathrm{p}<0.001)$. In biochemical analysis, the serum calcium level was decreased whereas the alkaline phosphatase level was elevated significantly in boric acid group. Histopathologically, there were decreased number of osteoclasts and increased osteoblasts in boric acid group (Group III).

Conclusion: Systemic administration of boric acid prevents alveolar bone loss caused by experimental periodontitis in rats as evidenced by morphometric, histolopathologic and biochemical analyses.

Copy Right, IJAR, 2017,. All rights reserved.

\section{Introduction:-}

Periodontal disease is a chronic infection of the periodontium affecting the soft and mineralized tissues surrounding and supporting the teeth. It is well established that the main etiological factor for periodontitis is the host-microbial interaction in the gingival connective tissue, which leads to gingival inflammation, connective tissue destruction, pocket formation, alveolar bone loss, tooth mobility and finally the loss of teeth. ${ }^{1}$

The ultimate goal of periodontal therapy is to prevent further attachment loss and predictably restore the periodontal supporting structures that were destroyed or lost because of the periodontal disease in order to re-establish the architecture and function of the lost tissues. Traditional periodontal therapies have focused on the mechanical and 
chemical approaches to reduce the microbial load on the tooth surfaces. Most recently, host-modulating agents have been investigated and tried in the management of periodontal disease for minimizing the tissue destruction. ${ }^{2}$

Boron is a bioactive trace element. It is the fifth element in the periodic table, which contains characteristics of both metals and nonmetals. Boron is rich in nature as boric acid and borate and can be obtained in the diet through the consumption of fruits, vegetables and legumes. ${ }^{3}$

Boron supplied through the diet in physiological amounts, is known to affect various metabolic parameters. It also has a vital role in osteogenesis and the maintenance of bone. In boron deficiency, bone regeneration and development are affected, increasing the possibility of bone loss. Dietary supplementation of boron in animal models and humans have shown its important effects on metabolism of minerals ( $\mathrm{Ca}$ and $\mathrm{P}$ ), vitamin-D, enzymes, hormones, energy substances and the reactive oxygen species (ROS). ${ }^{4}$

In periodontal research, the use of experimental model is the primary step before entering into the clinical trials with new biomaterial or the therapeutic modalities. Rat is the most extensively studied rodent and Wistar or Spraguedawleyare the frequently used strains in the models of experimental periodontitis. In animals, the experimental periodontitis may be induced by using silk ligatures tied around the molars or by specific bacterial inoculations.

It is now generally believed that disruption of the balance between osteoblasts and osteoclast activities by bacterial products and inflammatory cytokines constitutes one of the main underlying causes of inflammation-induced bone loss.

Biochemical markers such as serum calcium and alkaline phosphatase are important for assessment of bone metabolism rate and expression of the markers is closely related to osteoblast and osteoclast differentiation. ${ }^{5}$ similarly, the bone-specific alkaline phosphatase (BALP), an isoenzyme of alkaline phosphatase, has been implicated in the processes of bone formation. ${ }^{6}$

The reactive oxygen species (ROS) are oxygen derived molecules that act as powerful oxidants. ROS have the potential to induce damage to the cellular biomolecules taking place under oxidative stress conditions. There is large body evidence suggesting the role of ROS in several pathologic conditions such as diabetes mellitus, AIDS, arthritis, smoking, alcoholism, ageing, menopause and the periodontitis.

Since, there is limited data available in the scientific literature to correlate the effects of boric acid on histomorphometric changes with the biochemical markers; the present study was undertaken with the intent of evaluating the effect of systemic administration of boric acid on alveolar bone loss in ligature induced periodontitis rat model. It also aimed to correlate the effect of boric acid on alveolar bone loss with biochemical markers of bone metabolism i.e. serum calcium, alkaline phosphatase and plasma levels of ROMs.

\section{Mateialsand Methods:-}

ANIMALS: Thirty male Wistar rats (6-10 months old) weighing 300-350 gms were procured from the germ free Central Animal House, Department of Pharmacology, J. J. M. Medical College, Davangere, Karnataka, India. Rats were housed in polypropylene cages in groups of five per cage, using husk as their bedding. They were fed with standard commercial laboratory diet and water ad libitum, and maintained under a 12-h light/dark cycle at a temperature of $22^{\circ} \mathrm{C}$ and relative humidity of $50 \%$. The animals were given a week time to get acclimatized with the laboratory conditions. Handling was done in accordance with the guidelines given by National Centre for Laboratory Animal Sciences. Ethical approval for the study protocol was obtained from Animal Ethical Committee of Bapuji Pharmacy College (Institutional ethics committee registration number 105/1999/CPCSEA), Davangere, Karnataka, India, with the reference number of BEA.B.Ph/11/2012 on $20^{\text {th }}$ October 2012

\section{Grouping of Animals:-}

The selected rats were divided into the following 3 groups of 10 rats each according to the mode of treatment to be given to them for 11 days.

Group 1 (control) : Non-ligature group.

Group 2 (test) :Ligature induced periodontitis group.

Group 3 (test) :Ligature induced periodontitis group with gastric feeding of boric acid (3mg/kg). 


\section{Induction of periodontitis:-}

After the administration of adequate anesthesia (ether), rats were laid on their back and their upper and lower jaws were retracted open with the use of thick threads. Periodontitis was induced by placement of sterile 4-0 silk ligatures sub-marginally on the right second maxillary molar tooth. The sutures were checked regularly after placement and lost or loose sutures were replaced during the 11 day study period. ${ }^{7}$

Boric acid was procured from Nice Pharmaceuticals, Bangalore. The rats were weighed at the baseline and subsequently on daily basis and the drug dosage was adjusted accordingly. Rats were administered boric acid by gastric feeding every day in the morning at 10:00 am for 11 days. (0.9 mg boric acid/day).

\section{Biochemical Analysis:-}

At the end of the experimental period that is on day 11, blood samples were collected from the retro-orbital plexus of Ether sedated rats, by inserting capillary tubes into the medial canthus of the eye. The collected blood samples were immediately sent to the laboratory for analysis of serum calcium and alkaline phosphatase levels. Then the rats were sacrificed by overdose of Ether.

\section{Measurement of Alveolar Bone Loss In Rats:-}

The maxillae were DE fleshed and placed in preset position under the stereomicroscope and alveolar bone height was measured around right first maxillary molar, by recording the distance from the CEJ to the crest of alveolar bone. Measurements were made at three points on the buccal (mesio-buccal, mid-buccal, disto-buccal) and on the palatal sides (mesio-palatal, mid-palatal, disto-palatal) to quantify the alveolar bone level. The mean alveolar bone level was calculated around each tooth. To measure bone loss morphometrically, the images were captured using a 3 chip CCD camera (Preview, Media Cybernetics, Bethesda, MD, USA) attached to a stereomicroscope (Olympus, Tokyo, Japan) with $5 \mathrm{X}$ objective .

\section{Histopathologic Analysis:-}

Following morphometric analysis, the maxillae were decalcified by using 5-10 $\mathrm{ml}$ of $5 \%$ nitric acid for 4 weeks, which was confirmed by 'needling' the tissue. After decalcification, remnant acids was removed from the specimens by keeping them in distilled water for 1 day and dehydrated by means of alcohol at four different concentrations i.e. $70 \%, 80 \%, 90 \%$ and for 1 hour each and at 100\% concentration for overnight. Then, chloroform (100\%) was used for 2 hours to remove the alcohol from the specimens. The processed specimens were then embedded in a wax bath for 4 hours, mounted in paraffin wax and sectioned along the molars in a mesio-distal plane with the help of a rotary microtome machine (Leica R.M. 2155, Nussloch, Germany) to obtain the bone sections of $5 \mu$ thickness. The most central section of each tooth was selected and stained with hematoxylin-eosin (H \&E) to evaluate histological quantification of osteoclasts and visible osteoid formation.

\section{Biochemical Analysis:-}

\section{Reactive Oxygen Metabolites Estimation:-}

The blood samples were centrifuged at $3000 \mathrm{rpm}$ for 7-8 min and the plasma was separated and collected in a sterile plastic tube. The plasma aliquots were placed in ice box for transportation to the laboratory where they were stored at $-800 \mathrm{C}$.

$5 \mu 1$ plasma sample was mixed with $200 \mu 1$ of the prepared acetate buffer and $5 \mu 1$ of the chromogenic substrate and incubated for $5 \mathrm{~min}$ at $370 \mathrm{C}$. The $505 \mathrm{~nm}$ absorbance was recorded using a spectrophotometer. The measurement unit was expressed as Carratelli unit (Carr U). It has been established that 1 Carr U corresponds to $0.08 \mathrm{mg} / \mathrm{dL} \mathrm{H} 2 \mathrm{O} 2.6$

\section{Findings in the Morphometric Analysis of Alveolar Bone:-}

On morphometric analysis, group I showed lower alveolar bone loss than group II and III (p<0.001) fig.(1). Group II revealed increased bone loss compared to group I and III ( $\mathrm{p}<0.001)$ fig.(2). Boric acid administration in group III decreased the alveolar bone loss compared to Group II ( $<<0.001)$ fig. (3) but this reduction was still higher than Group I (p<0.001).

\section{Histopathological Findings:-}

On histopathologic analysis, Group I showed lower osteoclasts number than Group II and III ( $<<0.001)$ fig. (4). Group II revealed increased osteoclast numbers compared to Group I ( $\mathrm{p}<0.001)$ HS and III ( $\mathrm{p}<0.0001 \mathrm{HS})$ fig. (5). 
Boric acid administration in Group III decreased osteoclast numbers compared to Group II but this number was still higher than Group I ( $\mathrm{p}<0.001)$ figure (6).

Group I showed higher osteoblastic activity compared to Group II $(\mathrm{p}<0.001)$ and lower compared to Group III $(\mathrm{P}=$ $0.979)$ NS fig. (7). Group II revealed decreased osteoblast activity compared to Group I ( $p>0.05)$ and III ( $<<0.05)$ figure (8). Boric acid administration in group III increased the visible osteoblastic activity compared to Group I $(\mathrm{p}>0.05)$ and II $(\mathrm{p}<0.05)$ fig. $(9)$.

\section{Biochemical Findings:-}

On biochemical analysis, Group I showed lower serum calcium levels compared to Group II ( $<<0.001)$ and higher levels compared to Group III ( $\mathrm{p}=0.001$ ) but the same group showed higher alkaline phosphatase compared to Group II and III $(\mathrm{p}<0.001)$. Group II revealed elevation in serum calcium compared to Group I and III $(\mathrm{p}<0.001)$ and reduced alkaline phosphatase levels compared to Group I and III. However boric acid administration in Group III rats showed reduced levels of serum calcium and elevated levels of serum alkaline phosphatase compared to Group II $(\mathrm{p}<0.001)$.

\section{Reactive Oxygen Metabolites:-}

On biochemical analysis, Group I tissue ROS levels reflected lower values compared to Group II and III ( $<<0.001)$. Group II showed elevation of tissue ROS levels compared to Group I ( $<<0.001)$. However, boric acid administration in group III rats, demonstrated reduction in the tissue ROS levels compared to Group II ( $\mathrm{p}<0.001)$.

\section{Discussion:-}

The present study was undertaken with the intent of evaluating the effect of systemic administration of boric acid on alveolar bone loss in ligature induced periodontitis in the rat model. It also aimed to correlate the effect of boric acid on alveolar bone loss with biochemical markers of bone metabolism that is, serum calcium, alkaline phosphatase and plasma levels of ROMs. This model initiates a local host response in gingiva that involves the recruitment of inflammatory cells, generation of prostonoids and cytokines, elaboration of lytic enzymes, osteoclast activation leading to periodontal breakdown and alveolar bone loss.

Assessing bone turnover is critical to understand the course and treatment of periodontal disease. It can be assessed by measurement of enzymes or matrix proteins produced by osteoblasts or osteoclasts. Hence, biochemical markers are important tools in the assessment of rate of bone metabolism. Serum calcium and alkaline phosphatase are the most commonly assessed biomarkers. Serum calcium can be related to the changes seen during bone turnover. ${ }^{8}$ Similarly, alkaline phosphatase has been considered to be a good marker for bone formation. ${ }^{8,9}$ Expression of these bone markers is closely related to osteoblast and osteoclast differentiation and subsequent bone metabolism. ${ }^{9}$

Recent clinical studies suggested a positive association between periodontitis and blood ROS level or oxidative damage. It is possible that increased circulating ROS after periodontitis could be detrimental to systemic health. ${ }^{10}$ There is little literature available with regard to the relationship between blood ROS and periodontal condition; direct measurement of ROS is difficult because of its biochemical instability. To overcome this difficulty, a new technique of measuring reactive oxygen metabolites (ROM) has been developed which is considered to be useful in the assessment of systemic oxidative stress.

Bone loss is an inevitable consequence of periodontitis. It is measured as the distance from the cemento-enamel junction (CEJ) to the crest of the alveolar bone at selected and defined sites. The "distance method" of measuring bone loss is used widely, as it is not affected by the anatomical variations occurring at the root trunk and furcation areas $^{11,12}$. On the other hand, "area method" uses the area of the exposed root surfaces as a measure of bone loss, but it evaluates erroneously the areas of proximal surfaces of first and third molars where the effects of ligature placement on bone loss is not evident. ${ }^{12}$ Hence, the distance method at exact sites of ligature placement around the upper first molar was preferred to assess the alveolar bone loss in our study.

In the present study, control group (Group I) showed a mean alveolar bone loss of $0.42 \mathrm{~mm}$. This may be the result of growth and age-related bone remodeling process occurring in the jaw as a whole. Hence control groups are necessary to evaluate the portion of physiological bone loss in comparison with the bone loss that occurs in experimental periodontitis model. Ligature induced periodontitis group (Group II) showed a statistically highly 
significant increase in alveolar bone loss compared to the control group (Group I) (p<0.001). Saglamet al. ${ }^{1}$ and Demirer et al. ${ }^{7}$ found similar results.

This increased alveolar bone loss may be attributed to the pro-inflammatory cytokines and other bi-products of the inflammatory process involving the periodontium. The boric acid treated group (Group III) showed a statistically highly significant reduction in alveolar bone loss compared to ligated (Group II) and control group (Group I) $(\mathrm{p}<0.001)$. This reduction in alveolar bone loss may be explained by the anti-microbial, anti-inflammatory and the osteogenic properties of boric acid administered in the Group-III rats.

Bone remodeling occurs throughout life and involves bone resorption by osteoclasts and an equivalent amount of new bone formation by osteoblasts under physiologic conditions. This balance is impaired in pathologic conditions and results in skeletal abnormalities characterized by increased or decreased bone mass. In the present study, the histologic analysis revealed statistically highly significant difference in osteoclast numbers among the study groups $(\mathrm{p}<0.001)$. On the other hand, ligature induced periodontitis (Group II) showed a statistically highly significant increase $(\mathrm{p}<0.001)$ in the osteoclast number compared to the control group (Group I) because of increased numbers of osteoclasts appearing on the bone surfaces.

Ligated and boric acid treated group (Group III) showed a statistically non-significant difference seen as compared to the control group. The ligated and boric acid treated group (Group III) showed a statistically highly significant reduction in the osteoclast number compared to ligated group (Group II) ( $\mathrm{p}<0.001)$ which was similar to findings of Saglam et al ${ }^{1}$ and Demirer et al. ${ }^{7}$ Ligature placement increased the osteoclast number and so the alveolar bone loss. But, boric acid administration decreased the osteoclastic and increased the osteoblastic cell numbers, resulting into arrest of bone resorption and formation of new bone. This observation in boron group may be attributed to its antimicrobial, anti-inflammatory and osteogenic property.

On histologic analysis, osteoblastic activity showed a statistically significant difference among the study groups $(p<0.05)$ similar to the observations made by Demireret al. ${ }^{7}$ Ligature induced periodontitis group (Group II) showed a statistically significant decrease $(\mathrm{p}<0.05)$ in the osteoblastic activity compared to the control group (Group I). This finding can be compared with that of Demirer et al. ${ }^{7}$ However, a contradictory observations were made by Saglam et al. ${ }^{1}$ Boric acid treated group (Group III) showed a non-significant increase in the osteoblastic activity compared to control group (Group I) ( $\mathrm{p}>0.05)$. Ligated and boric acid treated group (Group III) showed a statistically highly significant increase in the osteoblastic activity compared to ligated group (Group II) $(\mathrm{p}<0.001)$.

Serum calcium level as a marker of bone remodeling process, are used to analyze the changes in the bone matrix. In the present study, serum calcium levels showed a statistically highly significant difference among the study groups $(\mathrm{p}<0.001)$. Ligature induced periodontitis group (Group II) showed a statistically highly significant elevation $(\mathrm{p}<0.001)$ in the serum calcium levels compared to the control group (Group I). Ligated and boric acid treated group (Group III) showed a non-significant increase in the serum calcium levels compared to control group (Group I) $(\mathrm{p}=0.001)$. Similarly, the ligated and boric acid treated group (Group III) showed a statistically highly significant reduction in the serum calcium levels compared to ligated group (Group II) $(\mathrm{p}<0.001)$. These findings may be attributed to the anti-inflammatory, anti-oxidant and osteogenic properties of boric acid, ultimately resulting into reduced bone loss and reduced serum calcium levels.

In the present study, serum alkaline phosphatase levels showed a statistically highly significant difference among the study groups $(\mathrm{p}<0.001)$. Ligature induced periodontitis group (Group II) showed a statistically highly significant reduction $(\mathrm{p}<0.001)$ in the serum alkaline phosphatase levels compared to the control group (Group I). The ligated and boric acid treated group (Group III) showed a statistically significant elevation in the serum alkaline phosphatase levels compared to ligated group (Group II) $(\mathrm{p}<0.05)$, suggesting that boric acid counteracted the negative effects of ligature on alveolar bone. Similar observations were made by Cetinkayaet al. ${ }^{13}$ in their study.

Studies have shown a positive association between periodontitis and blood ROS level or oxidative damage It is possible that increased circulating ROS after periodontitis could be detrimental to systemic health. In the present study, the plasma ROM levels measured at baseline were significantly higher in (Group II and Group III) as compared to controls $(\mathrm{p}<0.001)$. As plasma ROM is considered to be a reliable indicator of ROS in blood, ${ }^{14,15}$ an increase of plasma ROM in an otherwise chronic periodontitis cases indicates that chronic periodontal disease can increase ROS levels in blood. Thus our study establishes that there exists a positive association between 
periodontitis and blood ROS levels and reiterates that ROS produced in the periodontal lesion may spread to the blood stream. These results are in agreement with the observations made by Tamaki et al. ${ }^{14}$, Akalin et al ${ }^{16}$ and Baltaciog et al in their respective studies.

Ligature induced periodontitis group (Group II) showed a statistically highly significant increase $(\mathrm{p}<0.001)$ in the plasma ROMs levels with mean value of 0.14 as compared to the control group (Group I). Ligature and boric acid treated group (Group III) displayed a statistically highly significant reduction in plasma ROMs levels with mean value of 0.27 as compared to Group II rats $(\mathrm{p}<0.001)$. The anti-inflammatory and the anti-oxidant effects of boric acid could be responsible for reduction of ROMs in the present study.

Table 1:-Comparison of alveolar bone loss among and between study groups.

\begin{tabular}{|c|c|c|c|c|c|}
\hline \multirow[t]{2}{*}{ Groups } & \multicolumn{2}{|c|}{ Alveolar bone loss (mm) } & \multirow[t]{2}{*}{ F value $^{*}$} & \multicolumn{2}{|c|}{ Pairwise comparison $^{* * *}$} \\
\hline & Mean & SD & & Groups & p value \\
\hline Group 1 & 0.42 & 0.11 & $\begin{array}{c}69.614, \\
\mathrm{P}<0.001 \mathrm{HS}\end{array}$ & Gr I \& Gr II & $\begin{array}{c}0.0001 \\
\mathrm{p}<0.000 \mathrm{HS}\end{array}$ \\
\hline Group 2 & 0.91 & 0.10 & & Gr I \& Gr III & $\mathrm{p}=0.35 \mathrm{NS}$ \\
\hline Group 3 & 0.54 & 0.64 & & Gr II \& Gr III & $\begin{array}{c}0.0001 \\
\mathrm{p}<0.0001 \mathrm{HS}\end{array}$ \\
\hline
\end{tabular}

"One Way ANOVA test

** Post hoc Tukey test

Table II:-Comparison of Osteoclast number among and between study groups.

\begin{tabular}{|c|c|c|c|c|c|}
\hline \multirow{2}{*}{ Groups } & \multicolumn{2}{|c|}{ Osteoclast number } & \multirow{2}{*}{ F value $^{*}$} & \multicolumn{2}{|c|}{ Pairwise comparison $^{* * *}$} \\
\cline { 2 - 3 } \cline { 5 - 5 } & Mean & SD & & Groups & p value \\
\hline Group I & 2.70 & 1.49 & 135.67, & Gr I \& Gr II & $\mathrm{p}<0.001 \mathrm{HS}$ \\
\hline Group II & 17.10 & 3.11 & $\mathrm{P}<0.001 \mathrm{HS}$ & $\mathrm{Gr}$ I \& Gr III & $\mathrm{P}=0.979 \mathrm{NS}$ \\
\hline Group III & 2.50 & 1.90 & & Gr II \& Gr III & $\mathrm{p}<0.0001 \mathrm{HS}$ \\
\cline { 5 - 5 } & & &
\end{tabular}

One Way ANOVA test

${ }^{* *}$ Post hoc Tukey test

Table III:- Comparison of Osteoblast activity among and between study groups.

\begin{tabular}{|c|c|c|c|}
\hline \multirow{2}{*}{ Groups } & \multicolumn{2}{|c|}{ Osteoblast activity } & \multirow{2}{*}{ p value* } \\
\cline { 2 - 3 } & $\mathbf{0}$ & $\mathbf{1}$ & \multirow{2}{*}{$\begin{array}{c}\text { p value }=0.38 \\
\text { p }<0.05 \mathrm{NS}\end{array}$} \\
\hline Group I & 4 & 6 & \\
\hline Group II & 6 & 7 & \\
\hline
\end{tabular}

Kruskal Wallis ANOVA test

Table IV:-Comparison of serum calcium level among and between study groups.

\begin{tabular}{|c|c|c|c|c|c|}
\hline \multirow[t]{2}{*}{ Groups } & \multicolumn{2}{|c|}{ Calcium (mg/dL) } & \multirow[t]{2}{*}{ F value* } & \multicolumn{2}{|c|}{ Pairwise comparison ${ }^{* *}$} \\
\hline & Mean & SD & & Groups & p value \\
\hline Group I & 10.34 & 0.66 & 71.396, & Gr I \& Gr II & $p<0.001 \mathrm{HS}$ \\
\hline Group II & 12.76 & 0.90 & $\mathrm{p}=0.001 \mathrm{HS}$ & Gr I \& Gr III & $\mathrm{p}=0.001 \mathrm{HS}$ \\
\hline Group III & 9.06 & 0.47 & & Gr II \& Gr III & $\mathrm{p}<0.001 \mathrm{HS}$ \\
\hline
\end{tabular}

* One Way ANOVA test ${ }^{* *}$ Post hoc Tukey test

Table V:- Comparison of serum alkaline phosphatase level among and between study groups

\begin{tabular}{|c|c|c|c|c|c|}
\hline \multirow{2}{*}{ Groups } & \multicolumn{2}{|c|}{$\begin{array}{c}\text { Alkaline } \\
\text { phosphatase (U/L) }\end{array}$} & \multirow{2}{*}{ F value } & \multicolumn{2}{c|}{ Pairwise comparison } \\
\cline { 2 - 3 } & Mean & SD & & \multicolumn{2}{|c}{} \\
\cline { 2 - 3 } & & Groups & p value \\
\hline Group I & 781.61 & 43.33 & \multirow{2}{*}{$77.88 \mathrm{p}<0.001 \mathrm{HS}$} & Gr I \& Gr II & $\mathrm{p}<0.001 \mathrm{HS}$ \\
\cline { 2 - 3 } Group II & 537.30 & 29.68 & & Gr I \& Gr III & $\mathrm{p}<0.001 \mathrm{HS}$ \\
\hline Group III & 650.67 & 57.00 & & Gr II \& Gr III & $\mathrm{p}<0.001 \mathrm{HS}$ \\
\hline
\end{tabular}

* One Way ANOVA test

${ }^{* *}$ Post hoc Tukey test 
Table VI:-Comparison of inflammatory cell infiltration among and between.

\begin{tabular}{|c|c|c|c|c|c|c|c|}
\hline \multirow[t]{2}{*}{ Groups } & \multicolumn{3}{|c|}{ Inflammatory cell infiltration } & \multirow[t]{2}{*}{ H value* } & \multicolumn{3}{|c|}{ Pairwise comparison $^{* * *}$} \\
\hline & $\mathbf{0}$ & 1 & 2 & & Groups & Mean rank & p value \\
\hline Group I & 11 & 4 & 0 & 19.708 & Gr I \& Gr II & 3.80 & $\mathrm{p}<0.001 \mathrm{HS}$ \\
\hline Group II & 0 & 5 & 10 & $\mathrm{p}<0.001$ & Gr I \& Gr III & 0.651 & $\mathrm{P}=0.529 \mathrm{NS}$ \\
\hline Group III & 0 & 12 & 3 & & Gr II \& Gr III & 3.7 & $\mathrm{p}<0.001 \mathrm{HS}$ \\
\hline
\end{tabular}

Table VII:- Comparison of Plasma Reactive Oxygen Metabolites (ROMs) level among and between study groups. * One Way ANOVA test ${ }^{* *}$ Post hoc Tukey test

\begin{tabular}{|c|c|c|c|c|c|}
\hline \multirow[t]{2}{*}{ Groups } & \multicolumn{2}{|c|}{$\begin{array}{c}\text { Plasma Reactive Oxygen } \\
\text { Metabolites (ROMs) } \\
\end{array}$} & \multirow[t]{2}{*}{ F value $^{*}$} & \multicolumn{2}{|c|}{ Pairwise comparison ${ }^{* * *}$} \\
\hline & Mean & SD & & Groups & p value \\
\hline Group I & 0.37 & 0.05 & \multirow{3}{*}{$\begin{array}{c}51.14 \\
\mathrm{p}=0.001 \mathrm{HS}\end{array}$} & Gr I \& Gr II & $\mathrm{p}<0.001 \mathrm{HS}$ \\
\hline Group II & 0.51 & 0.07 & & Gr I \& Gr III & $\mathrm{p}<0.001 \mathrm{HS}$ \\
\hline Group III & 0.23 & 0.06 & & Gr II \& Gr III & $\mathrm{p}<0.001 \mathrm{HS}$ \\
\hline
\end{tabular}

Photomicrograph showing alveolar bone loss values under a stereomicroscope

Fig 1:-Group I.

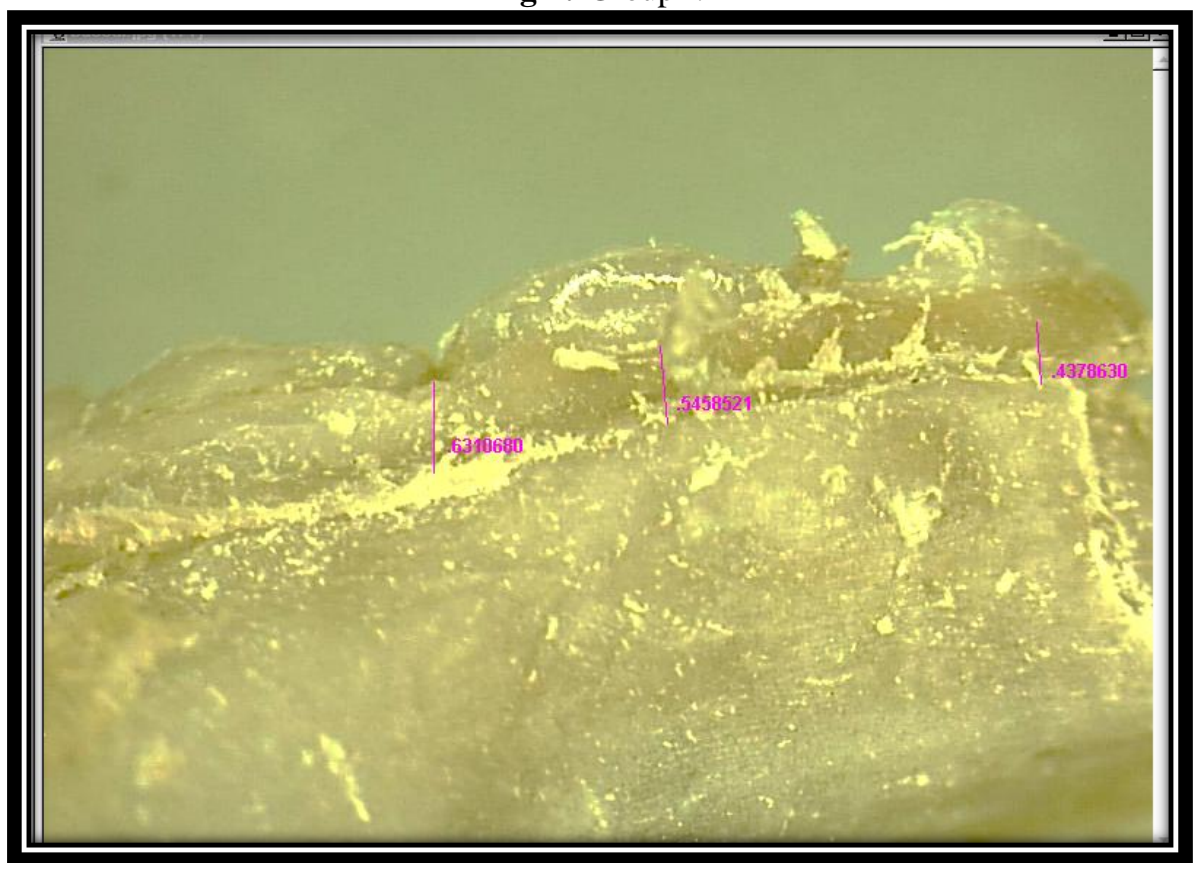


Fig 2:- Group II.

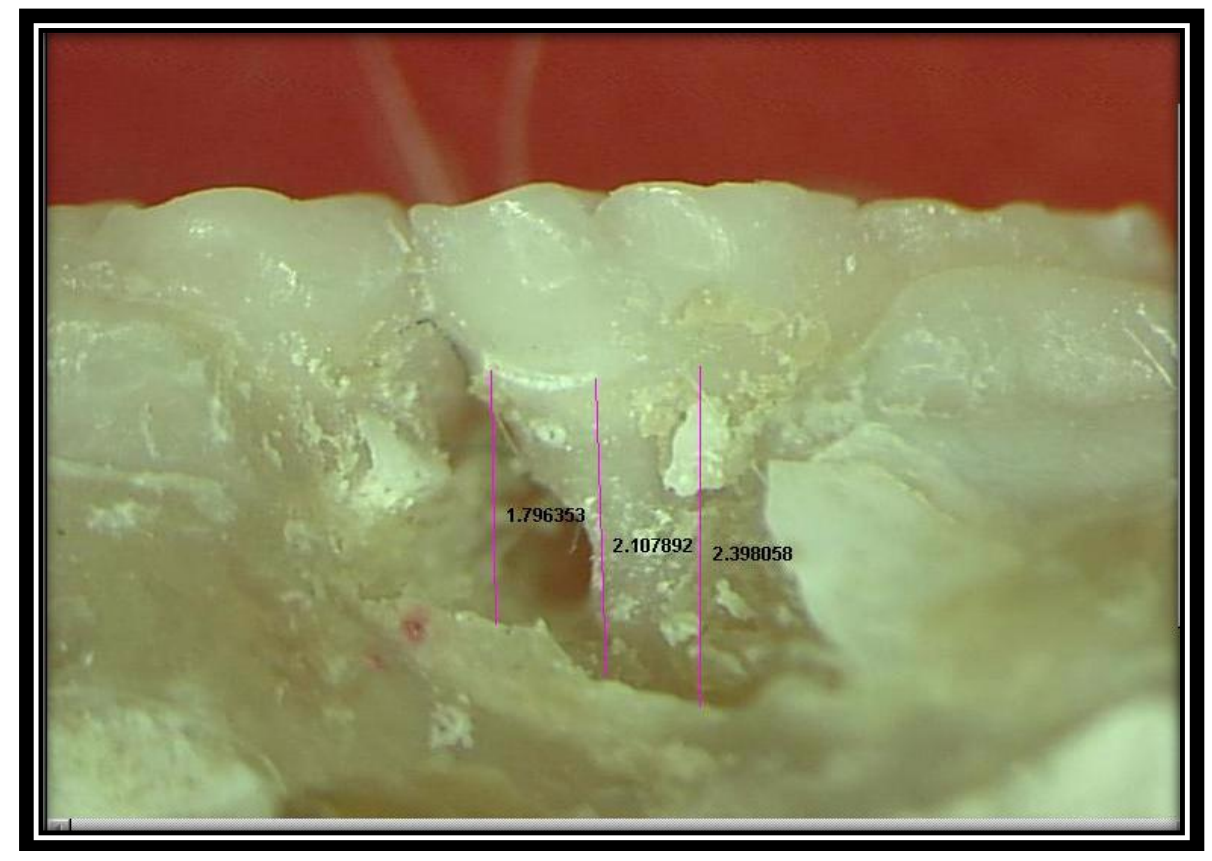

Fig 3:- Group III

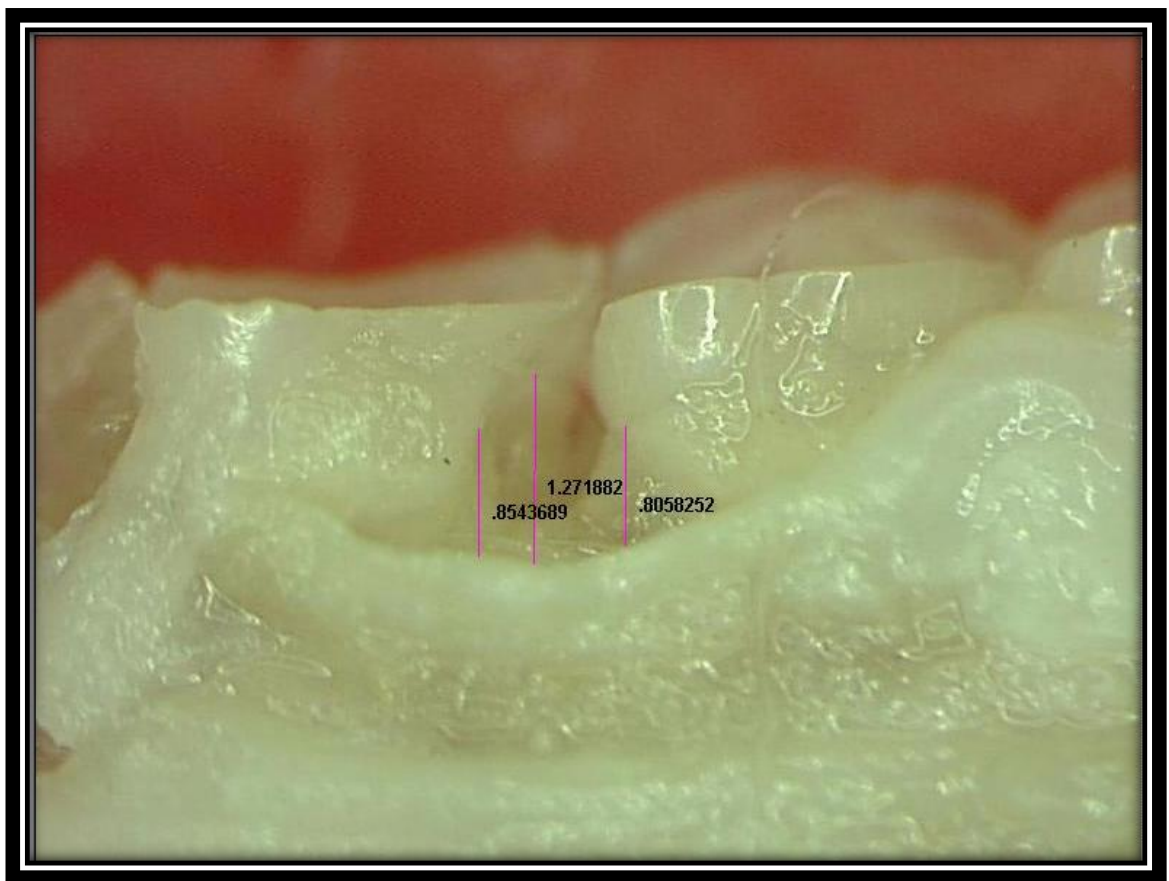


Histology photograph showing osteoclastic activity under research microscope

Fig 4:-Group I with osteoclasts.

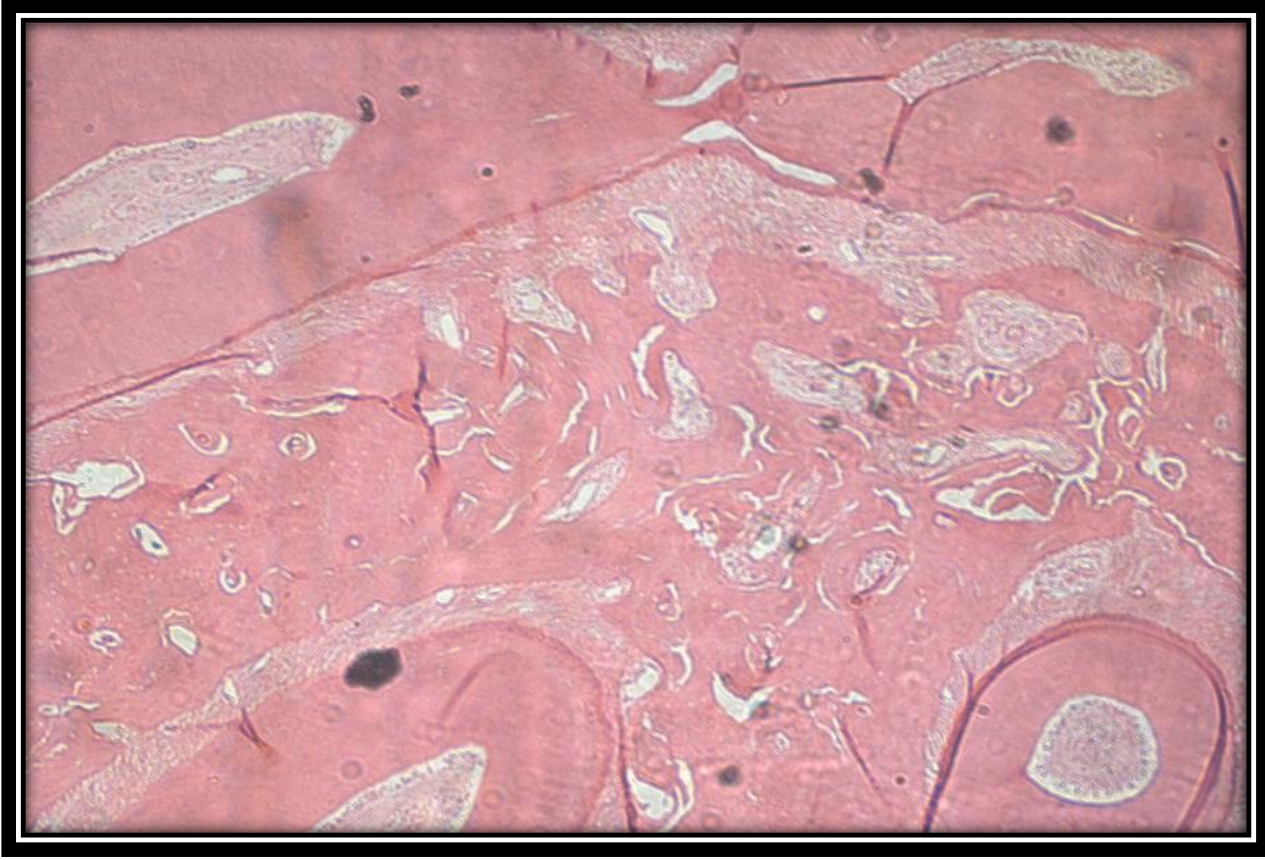

Fig 5:- Group II with osteoclasts.

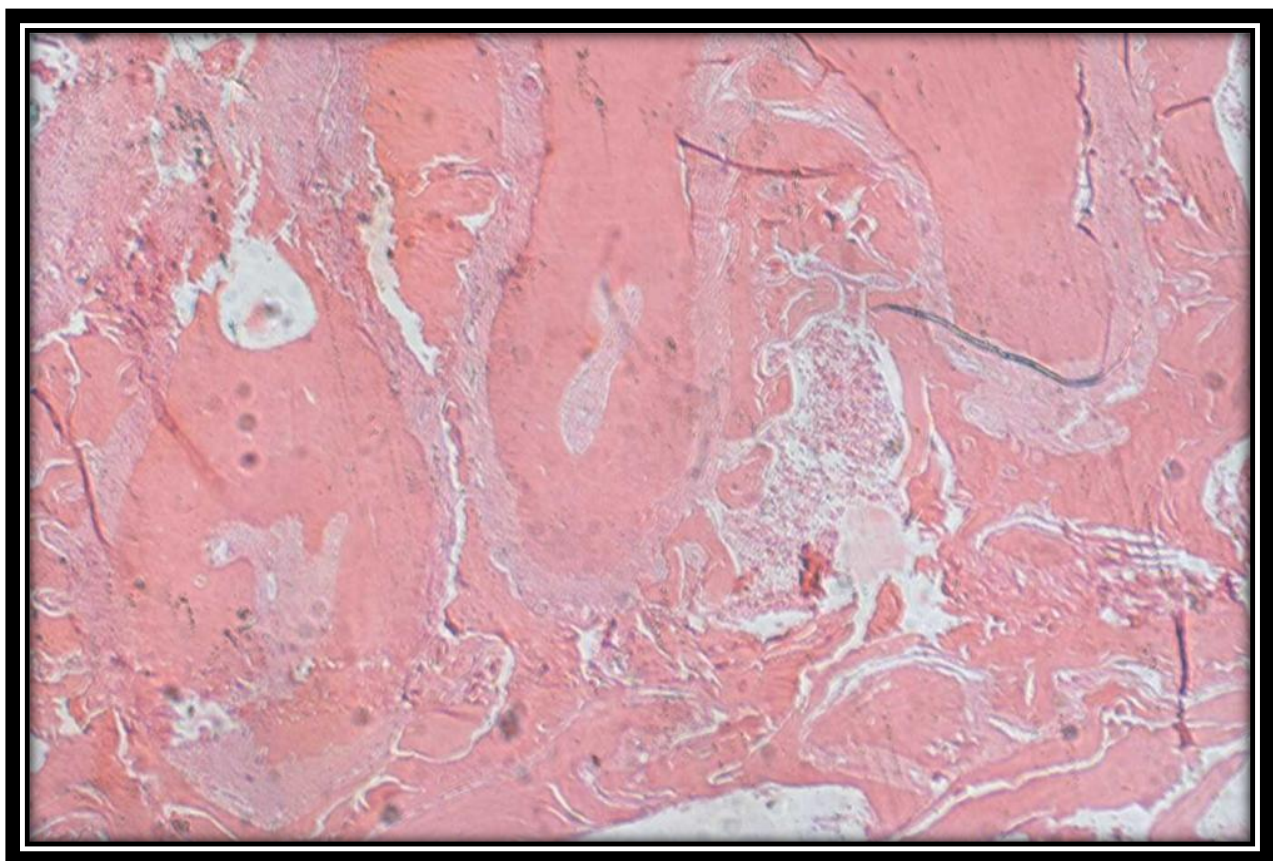




\section{Histology photograph showing osteoclastic activity under research microscope}

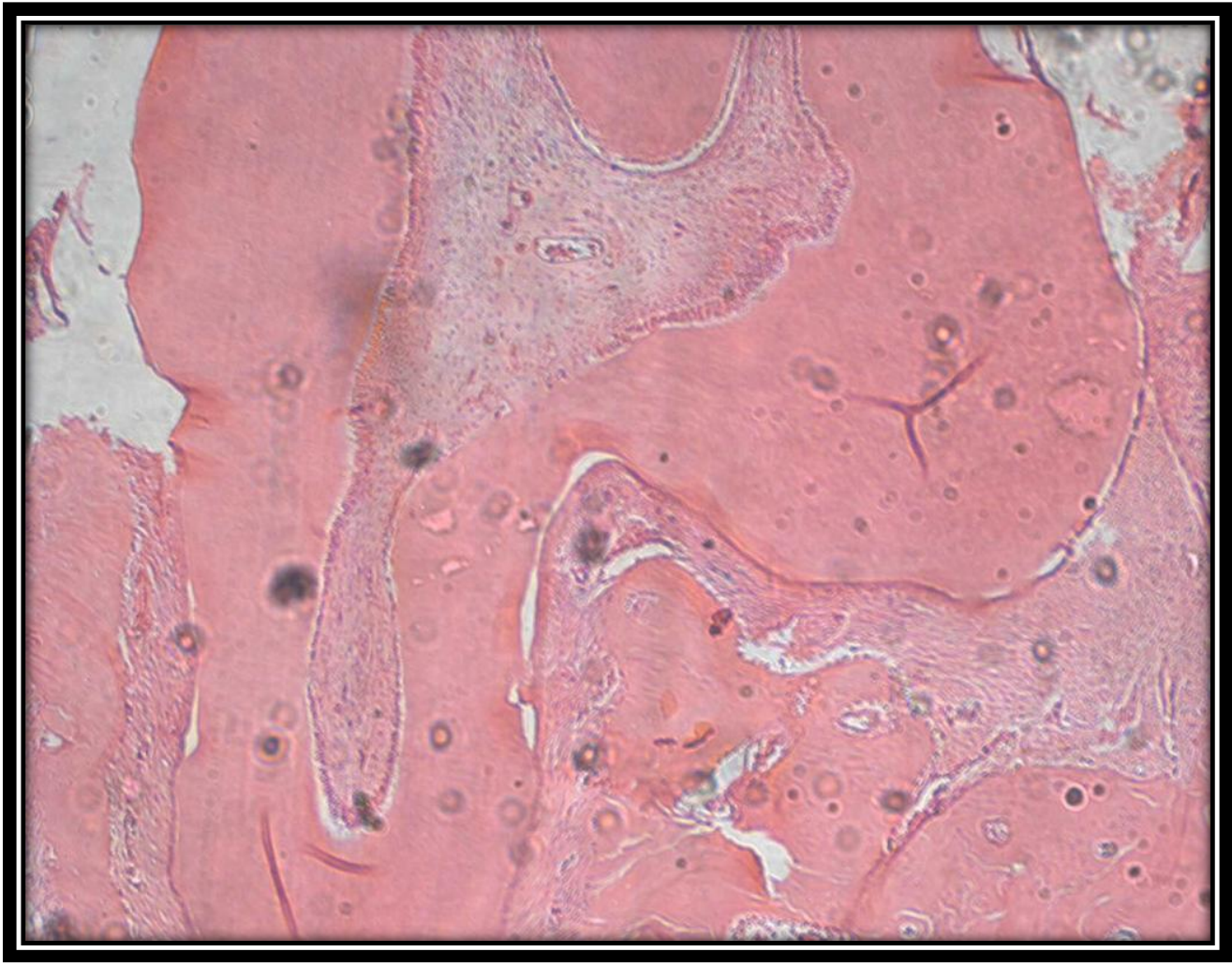

Fig 6:-Group III with osteoclasts.

\section{Histology photograph showing osteoblastic activity under research microscope}

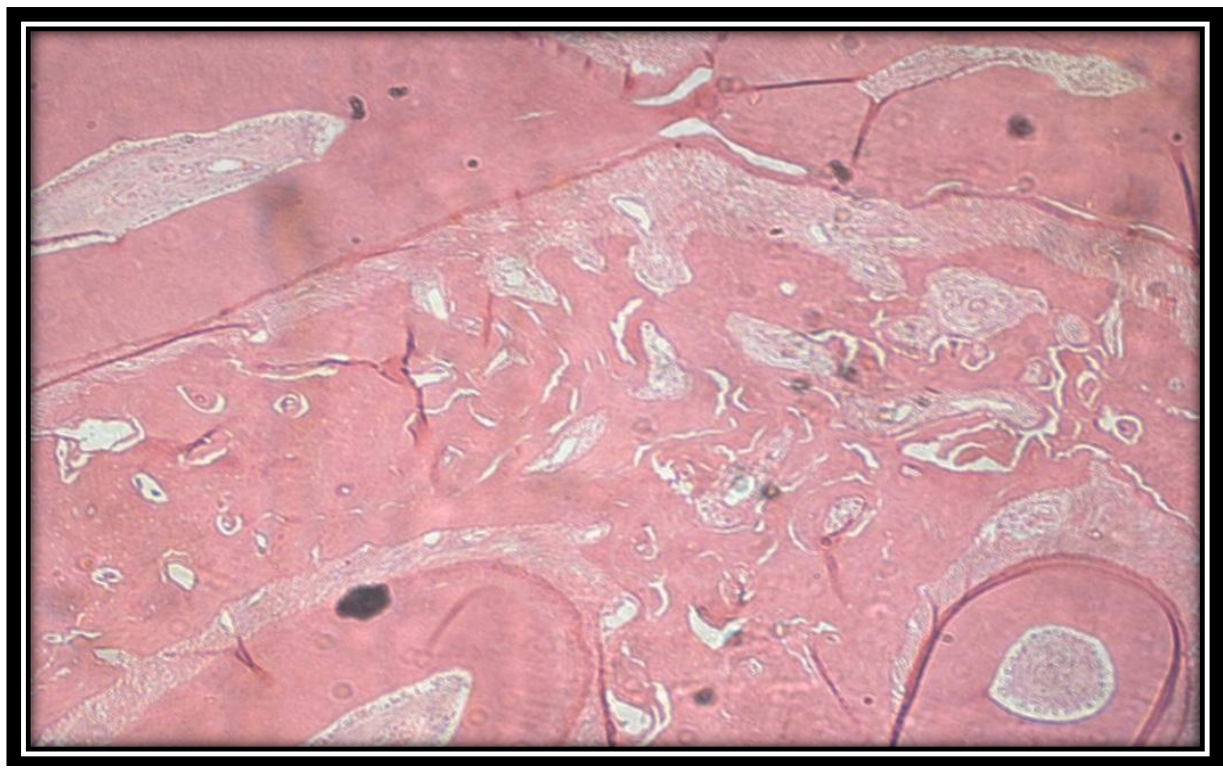

Fig 7:-Group I rats showing visible osteoblastic activity. 


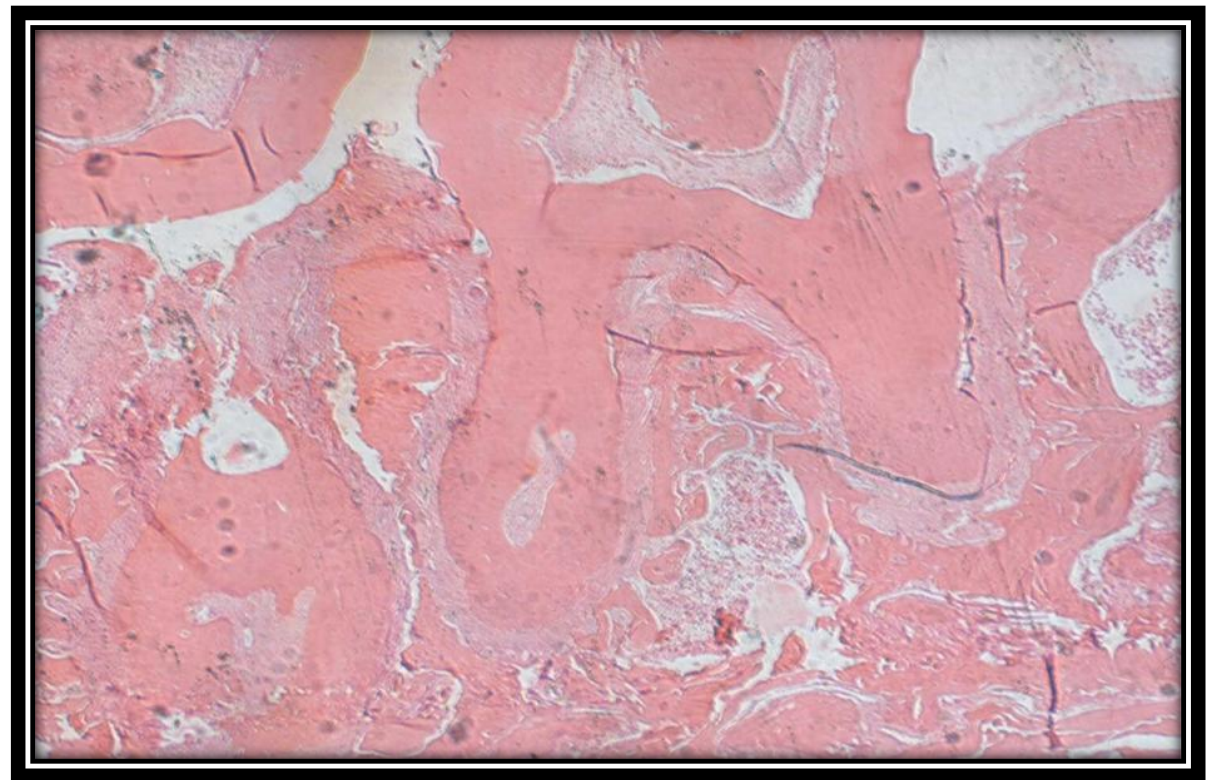

Fig 8:-Group II rats showing NO visible osteoblastic activity.

\section{Histology photograph showing osteoblastic activity under research microscope}

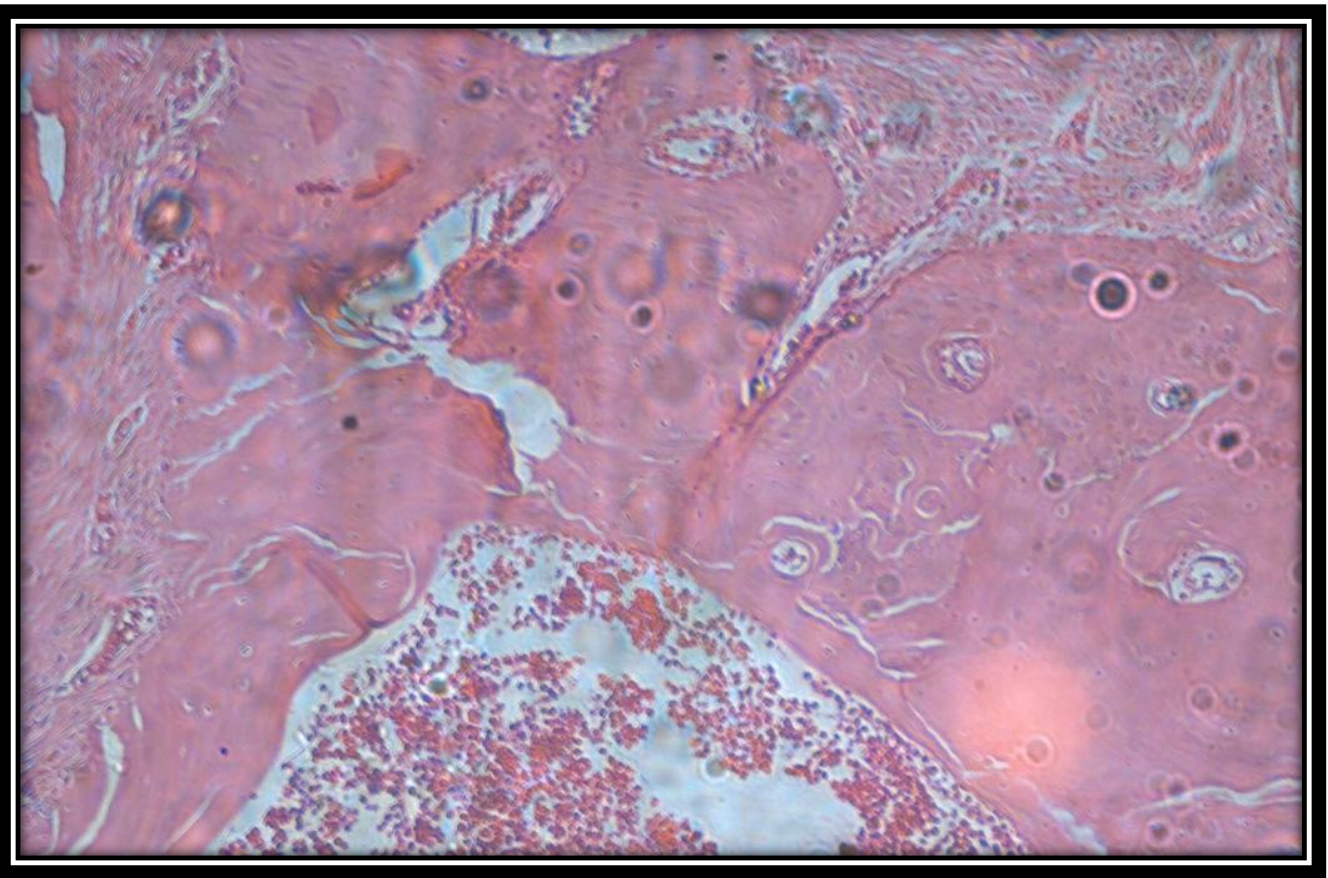

Fig 9:-Group III rats showing visible osteoblasticactivity. 


\section{Bibliography:-}

1. Saglam M, Hatipoglu M, Koseoglu S, Esen HH, Kelebek S. Boric acid inhibits alveolar bone loss in rats by affecting RANKL and osteoprotegerin expression. J Periodontal Res 2014;49:472-9.

2. Krayer JW, Renata SL, Kirkwood KL. Non-surgical chemotherapeutic treatment strategies for the management of periodontal diseases. Dent Clin N Am 2010; 54:13-33.

3. Prentice A, Schoenmakers I, Laskey MA, de Bono S, Ginty F, Goldberg GR. Nutrition and bone growth and development. ProcNutrSoc 2006;65:348-60.

4. Ince S, Kucukkurt I, Cigerci IH, FatihFidan A, Eryavuz A. The effects of dietary boric acid and borax supplementation on lipid peroxidation, antioxidant activity, and DNA damage in rats. J Trace Elem Med Biol 2010;24:161-4.

5. Amarasena N, Yoshihara A, Hirotomi T, Takano N, Miyazaki H. Association between serum calcium and periodontal disease progression in non-institutionalized elderly. Gerodontology2008;25:245-50.

6. Whyte MP.Physiological role of alkalinephosphataseexplored in hypophosphatasia.Ann New York AcadSci 2010;1192:190-200.

7. Demirer S, Kara MI, Erciyas K, Ozdemir H, Ozer H, Ay S. Effects of boric acid on experimental periodontitis and alveolar bone loss in rats. Arch Oral Biol 2012;57:60-5.

8. Altundal $\mathbf{H}$, Güvener $\mathbf{O}$. The effect of alendronate on resorption of the alveolar bone following tooth extraction. Int J Oral MaxillofacSurg 2004; 33:286-93.

9. Tobiume H, Kanzaki S, Hida S, Ono T, Moriwake T, Yamauchi S, et al. Serum bone alkaline phosphatase isoenzyme levels in normal children and children with growth hormone $(\mathrm{GH})$ deficiency: a potential marker for bone formation and response to GH therapy. J ClinEndocrinolMetab 1997; 82:2056-61.

10. Tamaki N, Tomofuji T, Ekuni D, Yamanaka R, Yamamoto T, Morita M. Short-term effects of non-surgical periodontal treatment on plasma level of reactive oxygen metabolites in patients with chronic periodontitis. $\mathbf{J}$ Periodontol 2009; 80:901-6.

11. Buduneli E, Vardar S, Buduneli N, Berdeli AH, Türkoğlu O, Başkesen A, et al. Effects of combined systemic administration of low-dose doxycycline and alendronate on endotoxin-induced periodontitis in rats. $\mathrm{J}$ Periodontol 2004;75:1516-23.

12. Kuhr A, Popa-Wagner A, Schmoll H, Schwahn C, Kocher T. Observations on experimental marginal periodontitis in rats. J Periodontal Res 2004;39:101-6.

13. Cetinkaya BO, Acikgoz G, Keles GC, Ayas B, Korkmaz A. The effect of cyclosporine-A on alveolar bone in rats subjected to experimental periodontal disease. ToxicolPathol 2006;34:716-22.

14. Tamaki N, Tomofuji T, Ekuni D, Yamanaka R, Yamamoto T, Morita M. Short-term effects of non-surgical periodontal treatment on plasma level of reactive oxygen metabolites in patients with chronic periodontitis. $\mathrm{J}$ Periodontol 2009; 80:901-6.

15. Komatsu F, Kagawa Y, Sakuma M, Kawabata T, Kaneko Y, Otgontuya D, et al. Investigation of oxidative stress and dietary habits in Mongolian people, compared to Japanese people. NutrMetab (Lond) 2006;7:21.

16. Akalin FA, Baltacioğlu E, Alver A, Karabulut E. Lipid peroxidation levels and total oxidant status in serum, saliva and gingival crevicular fluid in patients with chronic periodontitis. J ClinPeriodontol 2007;34:558-65.

17. Baltacioğlu E, Akalin FA, Alver A, Değer O, Karabulut E. Protein carbonyl levels in serum and gingival crevicular fluid in patients with chronic periodontitis. Arch Oral Biol 2008;53:716-22. 